\title{
Life cycle of Ceratothoa oestroides, a cymothoid isopod parasite from sea bass Dicentrarchus labrax and sea bream Sparus aurata
}

\author{
Ivona Mladineo* \\ Institute of Oceanography and Fisheries, Laboratory of Aquaculture, PO Box 500, 21000 Split, Croatia
}

\begin{abstract}
Ceratothoa oestroides (Risso, 1826) (Isopoda: Cymothoida) is a protandric hermaphrodite parasite on a wide range of wild fish species. In recent years it has become a threat to cagereared fish facilities, where high fish density provides optimal conditions for transmission. Its impact on fish health and economical gain is significant, varying from growth retardation and decreased immunocompetency to direct loss due to mass mortalities of juvenile fishes. Because of the sheltered location of the parasite in the buccal cavity of fishes, chemotherapeutics are ineffective. An understanding of the $C$. oestroides life cycle and its behavioral mechanisms could prove constructive tools for the prevention and control of infection. This study describes the reproductive cycle of $C$. oestroides experimentally induced in different fish hosts and temperature regimes. Sea bream larvae Sparus aurata and $1 \mathrm{yr}$ annular sea bream Diplodus annularis were chosen as experimental models, and were held at 22 and $19.5^{\circ} \mathrm{C}$, respectively. The reproductive cycle of $S$. aurata was not completed within 4 mo (at which point the last larva died of severe anemia and respiratory distress), while that of the annular sea bream was completed successfully after 1 mo.
\end{abstract}

KEY WORDS: Ceratothoa oestroides $\cdot$ Experimental infection $\cdot$ Sea bream larvae $\cdot$ Annular sea bream

\section{INTRODUCTION}

Ceratothoa oestroides (Cymothoidae) is a ubiquitous fish parasite. It has been reported in 6 different fish families-Sparidae, Carangidae, Clupeidae, Maenidae, Scorpaenidea and Mugilidae, and has been most frequently isolated from the bogue bream Boops boops (Sparidae) (Charfi-Cheikhrouha et al. 2000). Trilles et al. (1989) found this parasite in the Bay of Boka Kotorska (Monte Negro) in bogue and also in Mediterranean horse-mackerel Trachurus mediterraneus, annular sea bream Diplodus annularis, common pandora Pagelus erythrinus, and pickerel Spicara smaris.

Female Ceratothoa oestroides bear embryonated eggs in the brood pouch that develop first into Stage I pullus, and then into Pulli II and III (with rudimentary periopods of VII pairs), and finally into Pullus IV, at which stage postlarval evolution begins (Trilles 1964b).
As a protandric hermaphrodite, the parasite passes through different developmental stages: male puberty, prolonged male puberty, transitory stage, female puberty and finally prolonged female puberty (Trilles 1969). During the male puberty stage, the parasite loses its swimming capacity and, once settled in the buccal cavity of a fish, it is incapable of active migration to another host. This fact is important in the epizootic evaluation of the route of infection.

After settlement in the host, the parasite begins hematophagic nourishment, which comprises alternating cyclic periods of blood-sucking and blood absorption by the intestine (Trilles 1969).

As a consequence of its sedentary life in the wellsheltered buccal cavity, the parasite has evolved some structural changes, e.g. a thinner cuticle, the last 3 pairs of pleopods transformed into respiratory organs and a thinner-walled incubation chamber (Trilles 1969). 
Since settlement on a host can take place only within a short period of its life cycle, constant fertility of the female is necessary, and Ceratothoa oestroides remain in reproductive condition throughout the year, with only seasonal variations in the fecundity rate. The highest prevalence of gravid females (90\%) is in July, with fecundity ranging from 40 to 396 eggs female f $^{-1}$ (Trilles 1964a).

This study investigated the host-parasite relationship and the parasite's biotic and abiotic environmental requirements during its life cycle.

\section{MATERIALS AND METHODS}

Wild annular sea bream Diplodus annularis caught in fish traps were inspected for the presence of paired buccal cymothoids, and 5 fish with cymothoids were transferred to concrete tanks $\left(2 \mathrm{~m}^{3}\right)$ receiving a continuous flow of seawater at the ambient temperature and salinity of the collection area.

After 3 mo, Stage II pulli were observed swimming freely on the pool surface and were harvested immediately. A total of 48 Stage II pulli were transferred to 2 glass aquaria. Aquarium 1 contained 1 annular sea bream caught in the wild with 1 male Ceratothoa oestroides in its buccal cavity (the female parasite had been removed), and was held at $18^{\circ} \mathrm{C}$. Aquarium 2 contained eight $70 \mathrm{~d}$ old sea bream larvae Sparus aurata, weighing $70 \mathrm{mg}$; these were fed on Pellet No. 0 and held at 21 to $22^{\circ} \mathrm{C}$; Stage II pulli were then introduced. When all sea bream had a parasite on their surface, the remaining pulli without a host (22), were transferred to Aquarium 1, in which the annular sea bream already contained a male adult isopod. This was done to avoid superinfection and the possible mortality of the sea bream larvae.

\section{RESULTS}

After $1 \mathrm{wk}$, all isopods had settled in the buccal cavity of their hosts and the sea bream larvae began exhibiting a marked difference in their size. Fig. 1 shows a ventral view of an adult parasite. At this time, the larvae were kahectic, emaciated, and suffered some mortalities. Pulli left the host shortly after its death and swam around attempting to attach themselves to a new host. Thus, after $1 \mathrm{wk}$ at $22^{\circ} \mathrm{C}$, the parasites had not yet moulted to adult males. At this time, pulli were observed changing their locality from the buccal cavity to the outside surface of the fish and then back to the operculum, with no obvious environmental trigger. Eventually, however, they always returned to the buccal cavity of the same host.
After a period of $60 \mathrm{~d}$, when a host died, the pulli were no longer capable of swimming, as they had matured to adult males.

At 113 d post-infection (p.i.) the last surviving sea bream larva displayed hypertrophy of the tongue that impeded closure of the mouth, and it was markedly debilitated. As hypertrophy progressed, the pulli remained settled in the buccal cavity. At $132 \mathrm{~d}$ p.i., the last larva displayed severe anemia and emaciation resulting from minimum food consumption.

Dead sea bream larvae displayed severe paleness of the gills and visceral organs, empty stomachs and distended guts filled with a serous liquid. The bile vesicle was enlarged and filled with thick, dark-green substance.

Parasitological examination showed negative. In one case, the tongue of the last sea bream larva was hypertrophied, pale and yellow, and obstructed the inflow of water.

Pulli released after the death of the larvae were 25.25 times their hatching length. In Aquarium 1, $2 \mathrm{~d}$ p.i., pulli successfully settled in the buccal cavity of the sea bream, which was already harboring an adult male parasite. The water was at ambient temperature, ranging from $18.2^{\circ} \mathrm{C}$ at the beginning of the trial to $20.5^{\circ} \mathrm{C}$ at the end of the trail. We anesthetized the fish $8 \mathrm{~d}$ p.i., and inspection of the buccal cavity revealed no pulli and only the adult male parasite. The fish ate well and showed no distress. However, 29 d p.i., juvenile Stage II pulli were noticed swimming vigorously on the surface of aquarium. The fish was again anesthetized, and a pair of adult isopods removed from the buccal cavity. The male isopod had grown 25.5 times its initial length. The adult female had not been measured at the beginning of the trial, as we had observed that, once

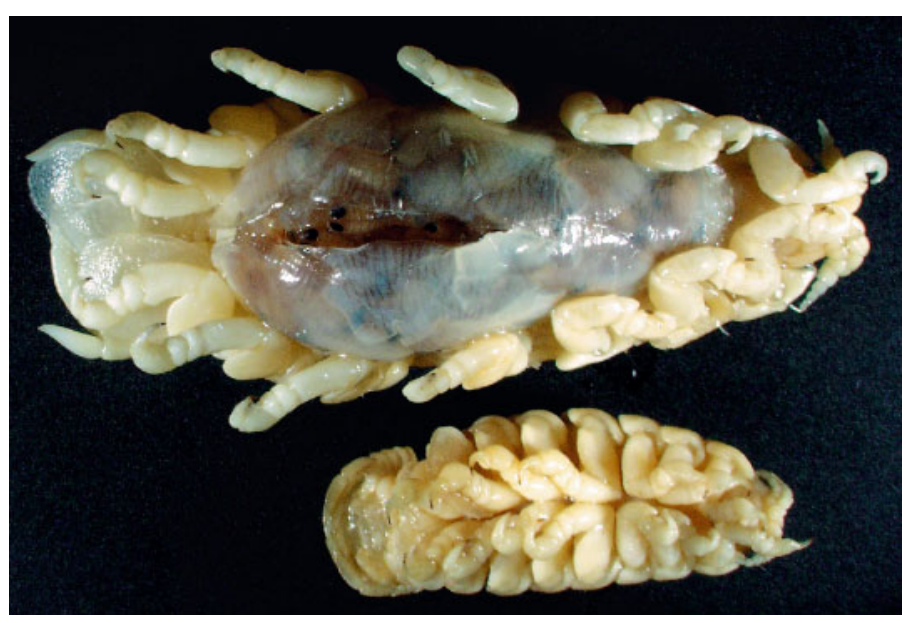

Fig. 1. Ceratothoa oestroides. Ventral view of male (bottom) and female harboring Stage II pulli 


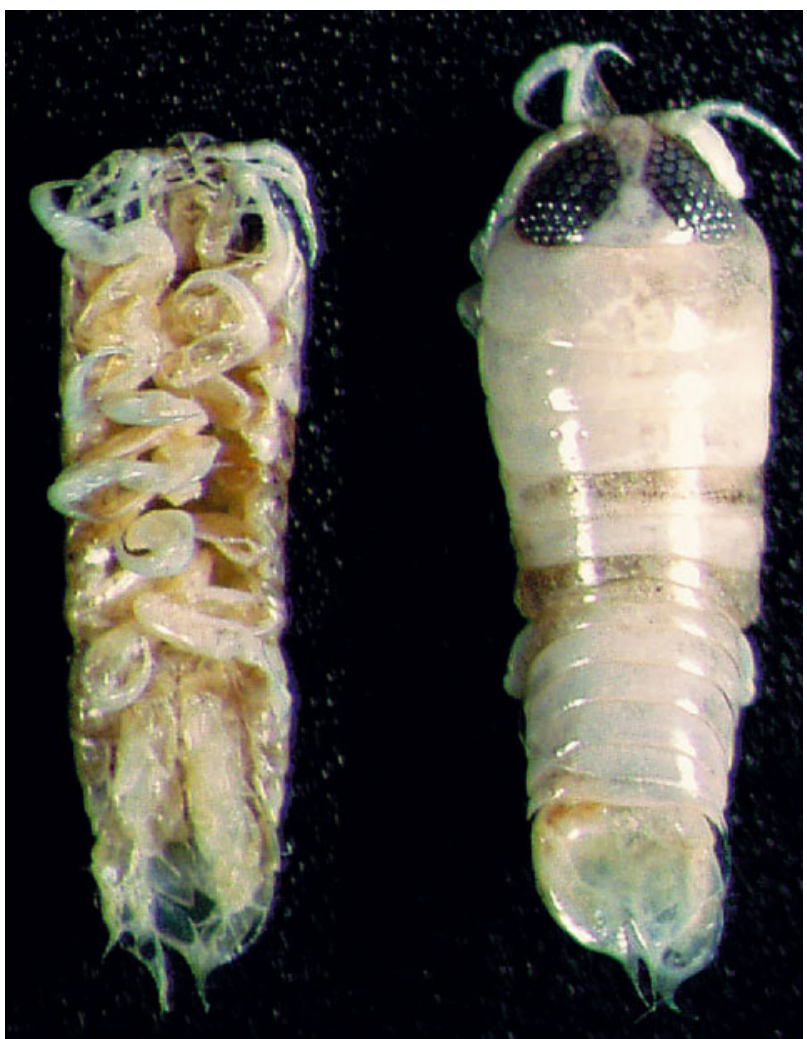

Fig. 2. Ceratothoa oestroides. Ventral and dorsal views of newly hatched Stage II pulli

removed for manipulation, parasites replaced in the buccal cavity were likely to be detached and regurgitated.

A new pair of isopods harbored by the annular sea bream produced 13 Stage II pulli (Fig. 2). These were left in the aquarium at a low temperature $\left(15^{\circ} \mathrm{C}\right)$ and survived a further week without a host. On the fifth day they were exhausted and sank to the bottom of the aquarium; only pleopod activity showed that they were still alive. Table 1 shows the development of sea bream larvae and the length of the infecting Stage II pulli over time.

Table 1. Sparus auratus. Weight (Wt) and length (L) of sea bream larvae, and length of isopod pulli Ceratothoa oestroides infecting them as a function of time (days of trial)

\begin{tabular}{|llcc|}
\hline Wt $(\mathrm{g})$ & L $(\mathrm{mm})$ & Days & Pulli L $(\mathrm{mm})$ \\
\hline 0.07 & 20.95 & 6 & 0.18 \\
0.07 & 20.55 & 6 & 0.21 \\
0.04 & 13.9 & 10 & 0.23 \\
0.11 & 16 & 19 & 0.27 \\
0.35 & 23.2 & 48 & 3.82 \\
0.81 & 40 & 29 & 5.05 \\
1.96 & 54.5 & 93 & 5.08 \\
\hline
\end{tabular}

\section{DISCUSSION}

Ceratothoa oestroides has a low host-specificity, and induces mortality and progressive growth retardation in fingerlings (Horton \& Okamura 2001), making potential outbreaks of this parasite a serious threat to aquaculture facilities. The parasite significantly depresses growth, reproduction and survivorship of infected fishes, as demonstrated by Adlard \& Lester (1994) for a population of wild fish in the field. In cagereared fishes growth can be reduced by $20 \%$ (Šarušić 1999, Horton \& Okamura 2001, Mladineo 2002a).

The behavior of the host and parasite at attachment, their interactions and viability under experimental conditions have been described elsewhere (Mladineo $2002 b)$. To date, there have been only a few reported cases of Cymothoidea infection in cage-reared sea bass with serious epizootic outbreaks (Bragoni et al. 1984, Papapanagiotou et al. 1999), and few of these have etiologically concerned Ceratothoa oestroides (Šarušić 1999, Horton \& Okamura 2001, Mladineo 2002a). There have been some attempts to develop an effective chemotherapy, but these have not gone beyond the experimental stage (Athanassopoulou et al. 2001a,b).

Research on the life cycle of isopods in controlled conditions (Adlard \& Lester 1994, 1995, Tsai et al. 1999), will hopefully lead to a more comprehensive and detailed understanding of patterns of infection. However, of recent studies under experimental conditions, only one related to this buccal cymothoid parasite (Mladineo 2002b).

In the present study, 2 different fish species of different age, held at different temperature regimes, were experimentally infected with Stage II pulli of Ceratothoa oestroides.

In annular sea bream 1 reproductive cycle of Ceratothoa oestroides at a mean temperature $19.5^{\circ} \mathrm{C}$ lasted $1 \mathrm{mo}$, while at a higher temperature $\left(22^{\circ} \mathrm{C}\right)$ with small sea bream larvae, the cycle was not completed after 4 mo. Infected sea bream larvae developed slowly, and did not attain the same weight as uninfected siblings, even when adapted to pellet food. Experimental infection was always successful, as a pair of pulli always settled in the buccal cavity. In the case of Ichthyoxenus fushanensis, a burrowing parasitic isopod of the freshwater fish Varicorhinus bacbatulus, Tsai et al. (1999) achieved a very low percentage of experimental infection $(0.4 \%)$, and the isopods died after $1 \mathrm{wk}$. However, C. oestroides was more aggressively active in the presence of a host than I. fushanensis, resulting in higher prevalence of infection in our trial.

However, juvenile Ceratothoa oestroides never parasitize adult sea bass, and adult $C$. oestroides cannot migrate from one host to another. As fingerlings grow 
in the wild, infected individuals die primarily because of parasitic impact and secondarily from other causes. Infected fingerlings rarely reach adult size, and therefore the number of infected bass decreases during development, thus lowering the prevalence of this isopod. For this reason, Stage II pulli do not regard fish larvae as an optimal food source, since the rapid deterioration of larvae infected with the isopod necessitates a search for another host.

After the first large-scale mortality of sea bream larvae 1 wk p.i., the Stage II pulli that had lost their hosts infected new ones, demonstrating that even after $1 \mathrm{wk}$ at $22^{\circ} \mathrm{C}$ they were still capable of swimming and had not moulted to the sessile pre-adult stage.

The pulli in sea bream larvae developed into sessile form only after $2 \mathrm{mo}$, because (1) they had to find a new host (and therefore needed to retain their swimming ability) and (2) space and food was scarce.

Even when larvae were exposed to superinfection by pulli, in every case only 1 pair settled in the mouth. In a few cases an extra solitary pulli was noticed attached on the gill arch, making its chances of development slim. A strong competitive mechanism at the neurohormonal level could exist between paired and unpaired isopods.

At $22^{\circ} \mathrm{C}$, pulli grew faster after the initial $3 \mathrm{wk}$ in the buccal cavity of bream larvae, paralleling the decreased growth rate of their host: at 3 wk p.i., sea bream had adapted to the presence of the parasite, and had begun to gain weight again.

Over a period of almost 4 mo, growth of sea bream pulli only equalled that of annular sea bream pulli at $1 \mathrm{mo}$, even though they were held at the optimal temperature range. Food and space requirements seemed to match better in annular sea bream.

Pulli are reported to be capable of infecting a host only at the precise maximum size of the latter (Trilles 1964a, Bello et al. 1997). However, in our study, attachment was successful over a wide range of larval lengths (from 2.1 to $13.4 \mathrm{~cm}$ ).

In only 1 mo the male isopod harbored in the annular sea bream changed to the female stage - triggered by the presence of newly settled pulli. When anesthetized and checked for the presence of pulli, the annular sea bream contained only the original male isopod, with the new pulli aborally behind it. The weak fertility and the small numbers of pulli resulted from their small size and their youth (females), but their vigor did not appear to be affected by any of the experimental conditions.

Ongoing experiments examining reproductive characteristics, brood resistance, activities and the life cycle of the isopod under different abiotic and biotic conditions may eventually clarify some crucial aspects of the epizootiology of Ceratothoa oestroides which could be helpful in prevention and therapy.
The cymothoid isopod Ceratothoa oestroides, emerging as a new fastidious and persistent parasite in cage-reared facilities, is easy to culture in experimental trials. The data presented herein on its sensitivity to mechanical handling after removal from the host, its predatory behavior when in contact with fishes, the length of its single reproductive cycle, and the activity of its newly hatched pulli and their survival in host-free conditions, together represent a useful tool for the prevention and control of the parasite in natural epizootic outbreaks of this parasite. The primary challenge in prevention and therapy will be the development of ecologically friendly tools. Potent but environmentally harmful chemotherapeutics should be employed only under controlled conditions. Experimental trials with in vitro observation of the parasite life cycle would help to break the Wogralic chain.

\section{LITERATURE CITED}

Adlard RD, Lester RJG (1994) Dynamics of the interaction between the parasitic isopod, Anilocra pomacentri, and the coral reef fish, Chromis nitida. Parasitology 109:311-324

Adlard RD, Lester RJG (1995) The life cycle and biology of Anilocra pomacentri (Isopoda, Cymothoidae), an ectoparasitic isopod of the coral reef fish, Chromis nitida (Perciformes, Pomacentridea). Aust J Zool 43:271-281

Athanassopoulou F, Bouboulis D, Martinsen B (2001a) In vitro treatments of deltamethrin against the isopod parasite Ceratothoa oestroides, a pathogen of seabass Dicentrarchus labrax L. Bull Eur Assoc Fish Pathol 21:26-29

Athanassopoulou F, Ragias V, Tavla J (2001b) Preliminary trials on the efficacy and toxicity of ivermectin against Lernathropus kroyeri Van Beneden, 1851 in cultured seabass Dicentrarchus labrax L. Aquac Res 32:77-79

Bello G, Vaglio A, Piscitelli G (1997) The reproductive cycle of Mothocya epimerica (Ispoda: Cymothoidae) a parasite of the sand smelt, Atherina boyeri (Osteichthyes: Atherinidae), in the Lesina Lagoon, Italy. J Nat Hist 31:1055-1066

Bragoni G, Romestand B, Trilles JP (1984) Parasitoses à Cymothoadien chez le loup Dicentrarchus labrax (Linaeus, 1758) en élevage. I. Ecologie parasitaire dans le cas d'étange de Diana (Haute-Corse) (Isopoda, Cyymothoidae). Crustaceana 47:44-51

Charfi-Cheikhrouha F, Zghidi W, Ould Yarba L, Trilles JP (2000) Le Cymothoidae (isopodes parasites de poissons) des côtes tunisiennes: écologie et indices parasitologiques. Syst Parasitol 46:143-150

Horton T, Okamura B (2001) Cymothoid isopod parasites in aquaculture: a review and case study of a Turkish sea bass (Dicentrarchus labrax) and sea bream (Sparus auratus) farm. Dis Aquat Org 46:181-188

Mladineo I (2002a) Prevalence of Ceratothoa oestroides (Risso, 1826), a cymothoid isopod parasite, in cultured sea bass Dicentrarchus labrax L. on two farms in the middle Adriatic Sea. Acta Adriat 43:97-102

Mladineo I (2002b) The mechanisms of infection of the buccal isopod Ceratothoa oestroides (Risso, 1826), in experimental conditions. Bull Eur Assoc Fish Pathol 22:304-310 
Papapanagiotou EP, Trilles JP, Photis G (1999) First record of Emetha andouini, a cymothoid isopod parasite, from cultured sea bas Dicentrarchus labrax in Greece. Dis Aquat Org 38:235-237

Šarušić G (1999) Preliminary report of infestation by isopod Ceratothoa oestroides (Risso, 1826), in marine cultured fish. Bull Eur Assoc Fish Pathol 19:110-113

Trilles JP (1964a) Note préliminaire sur quelques aspects de la reproduction chez les isopodes Cymothoidae Méditerranéens. Arch Zool Exp Gén 104:127-134

Trilles JP (1964b) A propos d'un fait particulier d'éthologie parasitaire chez les isopodes cymothoidae: la relation de

Editorial responsibility: Wolfgang Körting,

Hannover, Germany taille entre parasites et poissons. Note préliminaire. Vie Milieu 2:366-369

Trilles J P (1969) Recherches sur les Isopodes 'Cymothoidae' des côtes françaises. Aperçu général et comparatif sur la bionomie et la sexualité de ces Crustacés. Bull Soc Zool Fr 94:433-445

Trilles JP, Radujković BM, Romerstand B (1989) Parasites des poissons marins du Montenegro: isopodes. Acta Adriat 30:279-306

Tsai ML, Li JJ, Dai CF (1999) Why selection favors protandrous sex change for the parasitic isopod, Ichthyoxenus fushanesis (Isopoda: Cymothoidae). Evol Ecol 13:327-338

Submitted: December 10, 2002; Accepted: July 10, 2003

Proofs received from author(s): October 6, 2003 